Everyone at the ABTS thanks you for embracing the primary principle of MOC-life-long learning, which is consistent with our obligation to the public trust.

\section{ABTS Requirements for the 10-Year Milestone for Maintenance of Certification}

Diplomates of the American Board of Thoracic Surgery (ABTS) who plan to participate in the 10-Year Milestone for the Maintenance of Certification (MOC) process as Certified-Active must hold a currently valid, full, and unrestricted license to practice medicine. Diplomates must provide delineation of privileges at a hospital(s) accredited by the JCAHO or other institutions judged acceptable by the Board. Diplomates must also submit letter(s) of reference documenting their level of clinical activity and stature within the surgical community from the VP of Medical Affairs and one other responsible member on staff at their principal hospital. In addition, a valid ABTS certificate is an absolute requirement for entrance into the MOC process. If your certificate has expired, the only pathway for renewal of a certificate is to take and pass the Part I (written) and the Part II (oral) certifying examinations.

The CME requirements are 150 Category I credits over a five-year period. At least half of these CME hours need to be in the broad area of thoracic surgery. Category II credits are not accepted. Interested individuals should refer to the Board's Web site (www.abts.org) for a complete description of acceptable CME credits.

This year, the Board has changed the format of the MOC exam. Instead of taking the MOC exam at a testing center, the Board wants Diplomates to be aware that they will be taking the exam on their personal or office computer. The Diplomate will need to have a Web camera that will work in conjunction with the software for security purposes. The Board is transitioning to using SESATS as the mastery learning tool. Each time a Diplomate logs on to the site, he or she will be asked to hold his or her license (with a picture) to secure verification. The Diplomate will also be asked to provide a scan of the immediate area for security purposes. The online MOC exam must be completed during the time period of September 1, 2015, to October 31, 2015. Diplomates will be allowed to enter the online program 10 times for a total of 15 hours. If the exam is not completed within those parameters, it will be considered incomplete. The fee for sitting for the MOC secure exam is $\$ 125.00$. This fee covers the expenses associated with software needed to ensure the online exam is secure. Questions on the MOC exam will be modular, based on your specialty, and presented in a self-assessment format.

The American Board of Thoracic Surgery has voted to replace the requirement for mandatory database participation with Performance Improvement. The Board is requiring clinically active Diplomates to participate in a Practice Quality Improvement (PQI) project by January 2016. For those clinically active Diplomates who do not participate in a Board-approved database/registry, the Board will continue to require participation in the Professional Portfolio until the PQI process starts.

Diplomates may apply for MOC in the year their certificate expires or, if they wish to do so, they may apply up to two years before it expires. However, the new certificate will be dated 10 years from the date of expiration of their original certificate or most recent MOC certificate. In other words, going through the MOC process early does not alter the 10-year validation. Diplomates certified prior to 1976 (the year that time-limited certificates were initiated) are also required to participate in MOC if they wish to maintain valid certificates.

Information outlining the rules, requirements, and application deadline for the 10-year Milestone of MOC in thoracic surgery is available on the Board's Web site at www. abts.org. For additional information, please contact the American Board of Thoracic Surgery, 633 N Saint Clair St, Ste 2320, Chicago, IL 60611; telephone (312) 2025900; fax (312) 202-5960; E-mail: sesats@abts.org.

\section{Thoracic Surgery Foundation for Research and Education}

\section{Thoracic Surgery Foundation for Research and Education Research Grants}

The Thoracic Surgery Foundation for Research and Education (TSFRE) is pleased to announce six new cardiothoracic surgery research grants to support young investigators. "The TSFRE is pleased to fund the work of these six researchers. A committee of 22 cardiothoracic surgery research leaders in the field, including representatives from the nation's best ac- ademic institutions, selected the most worthy applications," said TSFRE President John H. Calhoon, MD. "Each application was analyzed thoroughly. It was a tough decision, but six proposals rose to the top. We know their contributions to the field will be significant."

The TSFRE Board of Directors accepted the recommendation of the TSFRE Research Committee and voted unanimously and enthusiastically to support the following projects:

1. Bryan A. Whitson, MD, PhD, The Ohio State University, Research Grant, \$80,000, MG53 Mitigation of 
Ischemia-Reperfusion Injury in Lung Transplantation: Mechanisms of Action in Ex-Vivo Lung Perfusion

2. Bo Yang, MD, PhD, University of Michigan, Research Grant, \$80,000, Determining the Effect of TGFBR Mutations on Myocardin-Dependent Smooth Muscle Differentiation Using Human iPS Cells

3. Heidi J. Reich, MD, Cedars-Sinai Medical Center, Braunwald Fellowship, \$30,000, Repeat Dosing of Allogeneic Cardiosphere-Derived Cells After Myocardial Infarction in Immunocompetent Rats

4. Hanghang Wang, MD, Duke University Medical Center, Braunwald Fellowship, \$60,000, Metabolomic and MicroRNA Signatures in Peripheral Blood of Patients With Thoracic Aortic Aneurysm

5. Jessica S. Donington, MD, NYU School of Medicine, Carolyn E. Reed Fellowship, \$10,000, Robotic Thoracic Surgery at the University of Alabama at Birmingham
6. Melanie A. Edwards, MD, Saint Louis University, Carolyn E. Reed Fellowship, \$10,000, Robotic Thoracic Surgery at the University of Alabama at Birmingham

TSFRE is a pivotal force for growth and vitality in cardiothoracic surgery, especially for research and academic career development. TSFRE was first established in 1988 as a 501(c)(3) not-for-profit charitable organization and is the charitable arm of The Society of Thoracic Surgeons. The foundation represents thoracic surgery in the United States and its research and educational initiatives support the broad spectrum of thoracic surgery. The mission of TSFRE is to foster the development of surgeon scientists in cardiothoracic surgery; increasing knowledge and innovation to benefit patient care. Contact: Priscilla S. Kennedy, TSFRE Executive Director, E-mail: pkennedy@tsfre.org; telephone: (312) 202-5868. 